Supporting Information for

\section{CHIRAL ORGANOCHLORINE PESTICIDE SIGNATURES IN GLOBAL}

\section{BACKGROUND SOILS}

Perihan B. Kurt-Karakus (1,2), Terry F. Bidleman (3*) and Kevin C. Jones (1)

1. Environmental Science Department, Lancaster University, Lancaster, LA1 4YQ, UK

2. Akdeniz University, Faculty of Engineering, Department. of Environmental Engineering,

07200, Antalya-TURKEY, 3. Centre for Atmospheric Research Experiments, Meteorological

Service of Canada, 6248 Eighth Line, Egbert, ON, L0L 1N0, CANADA

Author for correspondence at: Terry.Bidleman@ec.gc.ca, Tel: +1 70545833 22,

Fax: +17054583301
Deleted: Abstract $ๆ$

Chiral pesticides frequently undergo enantioselective degradation in soils.

Prior studies to characterize chiral

signatures have focused on treated

agricultural soils, rather than background

(untreated) soils, and tracking signatures

in the atmosphere, for source

apportionment purposes. In this study, we

investigated the chiral signatures in 65

background soils collected from different

locations across the world. The soils were

taken from different ecosystems (e.g.,

grasslands, forests) and the enantiomeric

fractions (EFs) of chiral chlordanes, $\alpha$

hexachlorocyclohexane $(\alpha-\mathrm{HCH})$ and

o,p'-DDT were determined. Chlordanes

in most of the soils showed the usual

pattern of enantioselective degradation

seen in agricultural soils, namely

depletion of $(+)$-trans-chlordane (TC) and

(-)-cis-chlordane (CC). However, some

samples showed opposite enantiomer

degradation patterns for TC, CC and

chlordane compound MC5. Correlations

were tested between the deviation of EFs

from racemic $(\mathrm{DEV}$ rac $=$ absolute value

of $0.500-\mathrm{EF})$, the percent soil organic

matter (\% SOM), annual mean

temperature and the ratio of $\mathrm{TC}$ to the

more stable compound trans-nonachlor

(TN). Significant positive correlations

were found between DEVrac and \% SOM

for $\mathrm{TC}$ and $\mathrm{CC}(\mathrm{p}=0.0022$ and 0.0031$)$,

but not for the other OCPs. No

significant correlations were found

between DEVrac and annual mean

temperature for any of the OCPs.

DEVrac for TC was negatively correlated

with the TC/TN ratio, but the regression

was driven by two points with high ratios

of TC/CC. Removing these two points

resulted in a nonsignificant regression.

The range of EFs for TC, CC, and $\alpha$ -

$\mathrm{HCH}$ in soils was greater than in ambient air, providing evidence of in situ

degradation after atmospheric deposition

in some cases. Variable EFs in soil

suggest that caution is needed when

considering the enantiomer signatures in air as a marker of volatilization of

weathered soil-derived organochlorines. ๆ व

Introduction

Many organochlorine pesticides (C

$\ldots[1]$

Deleted: ๆ

\section{9}

I

\}

\}

I

व

,Table S1. Supplementary Data 


\begin{tabular}{|c|c|c|c|c|}
\hline & Sample Code & PK 300 & PK 301 & PK 302 \\
\hline & Sampling Country / Region & Alaska & Antarctica & Australia \\
\hline & Landuse & Tundra & Nature reserve & Woodland \\
\hline & Latitude & 59.050 & -66.366 & -36.500 \\
\hline & Longitude & -158.500 & 110.589 & 150.033 \\
\hline & Sample Depth (cm) & $0-5$ & $0-5$ & $0-5$ \\
\hline & SOM \% & 37 & na & 10.7 \\
\hline & Annual Mean Temp (C) & -1.9 & -15 & 15 \\
\hline TC & Avrg EF & 0.391 & 0.500 & 0.495 \\
\hline CC & Avrg EF & 0.418 & na & 0.472 \\
\hline MC5 & Avrg EF & 0.492 & na & 0.522 \\
\hline$\alpha-\mathrm{HCH}$ & Avrg EF & 0.560 & 0.508 & 0.864 \\
\hline o,p'- DDT & Avrg EF & na & na & na \\
\hline & Sample Code & PK 303 & PK 304 & PK 305 \\
\hline & Sampling Country / Region & Australia & Australia & Bolivia \\
\hline & Landuse & Grazing & Forest & High altitude desert \\
\hline & Latitude & -30.840 & -32.120 & -22.920 \\
\hline & Longitude & 143.220 & 151.500 & -68.250 \\
\hline & Sample Depth (cm) & $0-5$ & $0-5$ & $0-5$ \\
\hline & SOM\% & 0.1 & 12.6 & 0.6 \\
\hline & Annual Mean Temp (C) & 15 & 18 & na \\
\hline TC & Avrg EF & 0.495 & 0.599 & 0.508 \\
\hline CC & Avrg EF & 0.495 & 0.464 & 0.411 \\
\hline MC5 & Avrg EF & 0.505 & 0.480 & na \\
\hline$\alpha-\mathrm{HCH}$ & Avrg EF & 0.335 & 0.313 & 0.497 \\
\hline o,p'- DDT & Avrg EF & na & na & 0.495 \\
\hline & Sample Code & PK 306 & PK 307 & PK 308 \\
\hline & Sampling Country / Region & Bolivia & Brazil & Brazil \\
\hline & Landuse & Scrub & Woodland & $\mathrm{XXX}$ \\
\hline & Latitude & -16.500 & -29.067 & -22.600 \\
\hline & Longitude & -67.583 & -51.600 & -48.300 \\
\hline & Sample Depth (cm) & $0-5$ & $0-5$ & $0-5$ \\
\hline & SOM\% & 68 & 0.2 & 14.6 \\
\hline & Annual Mean Temp (C) & 25 & 14 & 17.5 \\
\hline TC & Avrg EF & na & 0.473 & 0.457 \\
\hline CC & Avrg EF & 0.614 & 0.477 & 0.518 \\
\hline MC5 & Avrg EF & 0.443 & 0.483 & 0.480 \\
\hline$\alpha-\mathrm{HCH}$ & Avrg EF & 0.505 & na & 0.499 \\
\hline o,p'- DDT & Avrg EF & 0.533 & na & na \\
\hline
\end{tabular}


Table S1. (continued)

\begin{tabular}{|c|c|c|c|c|}
\hline & Sample Code & PK 309 & PK 310 & PK 311 \\
\hline & Sampling Country / Region & Brazil & Brazil & Canada \\
\hline & Landuse & Grassland, uncultivatec & Rainforest & Woodland \\
\hline & Latitude & -9.233 & -24.500 & 45.033 \\
\hline & Longitude & -35.333 & -44.600 & -76.683 \\
\hline & Sample Depth (cm) & $0-5$ & $0-5$ & $0-5$ \\
\hline & SOM\% & 1.7 & 25.9 & 20.9 \\
\hline & Annual Mean Temp (C) & 25 & 21 & 3 \\
\hline TC & Avrg EF & na & na & 0.358 \\
\hline CC & Avrg EF & na & na & 0.523 \\
\hline MC5 & Avrg EF & na & na & 0.510 \\
\hline$\alpha-\mathrm{HCH}$ & Avrg EF & 0.480 & 0.489 & 0.475 \\
\hline o,p'- DDT & TAvrg EF & 0.438 & na & 0.547 \\
\hline & Sample Code & PK 312 & PK 313 & PK 314 \\
\hline & Sampling Country / Region & Canada & Canada & Canada \\
\hline & Landuse & Park & Forest & Agricultural, grass \\
\hline & Latitude & 51.117 & 51.417 & 49.150 \\
\hline & Longitude & -114.117 & -116.483 & -98.800 \\
\hline & Sample Depth (cm) & $0-5$ & $0-5$ & $0-5$ \\
\hline & SOM\% & 36.7 & 50.7 & 12.5 \\
\hline & Annual Mean Temp (C) & 3 & 3 & 1.5 \\
\hline $\mathrm{TC}$ & Avrg EF & 0.421 & 0.412 & 0.407 \\
\hline $\mathrm{CC}$ & Avrg EF & na & 0.553 & 0.550 \\
\hline MC5 & Avrg EF & na & 0.517 & 0.441 \\
\hline$\alpha-\mathrm{HCH}$ & Avrg EF & na & 0.572 & 0.467 \\
\hline o,p'- DDT & Avrg EF & na & 0.444 & 0.507 \\
\hline & Sample Code & PK 315 & PK 316 & PK 317 \\
\hline & Sampling Country / Region & Canada & Canada & Canada, Montreal \\
\hline & Landuse & Old pasture & Tundra & grassland \\
\hline & Latitude & 43.983 & 78.880 & 45.500 \\
\hline & Longitude & -79.250 & -76.000 & -73.333 \\
\hline & Sample Depth (cm) & $0-5$ & $0-5$ & $0-5$ \\
\hline & SOM\% $\%$ & 5.2 & 31.5 & 24.1 \\
\hline & Annual Mean Temp (C) & 3 & -19 & 7 \\
\hline TC & Avrg EF & 0.444 & 0.466 & 0.382 \\
\hline CC & Avrg EF & 0.541 & 0.514 & 0.498 \\
\hline MC5 & Avrg EF & 0.479 & 0.488 & 0.532 \\
\hline$\alpha-\mathrm{HCH}$ & Avrg EF & 0.503 & 0.479 & 0.496 \\
\hline $0, p^{\prime}-$ DDT & TAvrg EF & 0.503 & 0.510 & 0.465 \\
\hline
\end{tabular}


Table S1. (continued)

\begin{tabular}{|c|c|c|c|c|}
\hline & Sample Code & PK 318 & PK 319 & PK 320 \\
\hline & Sampling Country / Region & Canada & Chile & Cyprus \\
\hline & Landuse & \multicolumn{2}{|c|}{ Pasture organic/National park } & Scrub \\
\hline & Latitude & 49.830 & -37.317 & 34.580 \\
\hline & Longitude & -96.830 & -71.683 & 32.420 \\
\hline & Sample Depth (cm) & $0-5$ & $0-5$ & $0-5$ \\
\hline & SOM \% & 2.2 & 2.5 & 3.3 \\
\hline & Annual Mean Temp (C) & 2.5 & 13 & 19.5 \\
\hline TC & Avrg EF & 0.442 & 0.533 & 0.434 \\
\hline CC & Avrg EF & 0.517 & 0.532 & 0.507 \\
\hline MC5 & Avrg EF & 0.524 & 0.591 & 0.435 \\
\hline$\alpha-\mathrm{HCH}$ & Avrg EF & 0.524 & 0.500 & 0.506 \\
\hline o,p'- DDT & Avrg EF & na & na & 0.537 \\
\hline & Sample Code & PK 321 & PK 322 & PK 323 \\
\hline & Sampling Country / Region & Ethiopia & France & Germany \\
\hline & Landuse & Grassland & Woodland & Pasture \\
\hline & Latitude & 7.300 & 46.583 & 47.717 \\
\hline & Longitude & 38.683 & 1.333 & 10.300 \\
\hline & Sample Depth $(\mathbf{c m})$ & $0-5$ & $0-5$ & $0-5$ \\
\hline & SOM\% & 4.2 & 4 & 11.2 \\
\hline & Annual Mean Temp (C) & 18 & 9 & 10 \\
\hline $\mathrm{TC}$ & Avrg EF & 0.450 & 0.371 & 0.443 \\
\hline $\mathrm{CC}$ & Avrg EF & 0.450 & 0.417 & 0.521 \\
\hline MC5 & Avrg EF & na & 0.440 & 0.509 \\
\hline$\alpha-\mathrm{HCH}$ & Avrg EF & 0.496 & 0.503 & na \\
\hline o,p'- DDT & Avrg EF & 0.511 & na & 0.477 \\
\hline & Sample Code & PK 324 & PK 325 & PK 326 \\
\hline & Sampling Country / Region & Germany & Ghana & Ghana \\
\hline & Landuse & Woodland & Rainforest & na \\
\hline & Latitude & 50.720 & 7.000 & 5.550 \\
\hline & Longitude & 7.070 & 3.000 & -0.250 \\
\hline & Sample Depth (cm) & $0-5$ & $0-5$ & $0-5$ \\
\hline & SOM\% $\%$ & 55.2 & 15 & 3.3 \\
\hline & Annual Mean Temp (C) & 10 & 32 & 32 \\
\hline TC & Avrg EF & 0.384 & na & na \\
\hline $\mathrm{CC}$ & Avrg EF & 0.494 & na & na \\
\hline MC5 & Avrg EF & 0.426 & na & na \\
\hline$\alpha-\mathrm{HCH}$ & Avrg EF & 0.529 & na & 0.487 \\
\hline o,p'- DDT & Avrg EF & 0.393 & na & na \\
\hline
\end{tabular}


Table S1. (continued)

\begin{tabular}{|c|c|c|c|c|}
\hline & Sample Code & PK 327 & PK 328 & PK 329 \\
\hline & Sampling Country / Region & Greenland & Hawaii & Iceland \\
\hline & Landuse & Rock, Icecap & tropical forest & na \\
\hline & Latitude & 68.000 & 21.330 & 63.980 \\
\hline & Longitude & -32.000 & -157.820 & -19.100 \\
\hline & Sample Depth (cm) & $0-5$ & $0-5$ & $0-5$ \\
\hline & SOM\% & 0.2 & 23.1 & 12.8 \\
\hline & Annual Mean Temp (C) & -15 & 24 & 5.7 \\
\hline TC & Avrg EF & na & 0.486 & 0.413 \\
\hline CC & Avrg EF & 0.582 & 0.528 & 0.344 \\
\hline MC5 & Avrg EF & na & 0.538 & 0.365 \\
\hline$\alpha-\mathrm{HCH}$ & Avrg EF & 0.521 & 0.471 & 0.522 \\
\hline $0, p^{\prime}-\mathrm{DDT}$ & Avrg EF & na & na & na \\
\hline & Sample Code & PK 330 & PK 331 & PK 332 \\
\hline & Sampling Country / Region & Ireland & Japan & Japan \\
\hline & Landuse & Grassland & subalpine woodland & na \\
\hline & Latitude & 53.333 & 36.250 & 36.000 \\
\hline & Longitude & -9.900 & 137.500 & 139.283 \\
\hline & Sample Depth (cm) & $0-5$ & $0-5$ & $0-5$ \\
\hline & SOM\% & 55.3 & 53.1 & 24.7 \\
\hline & Annual Mean Temp (C) & 9.5 & 9 & 9 \\
\hline TC & Avrg EF & 0.364 & 0.429 & 0.504 \\
\hline $\mathrm{CC}$ & Avrg EF & 0.534 & 0.521 & 0.492 \\
\hline MC5 & Avrg EF & 0.609 & 0.469 & 0.366 \\
\hline$\alpha-\mathrm{HCH}$ & Avrg EF & 0.489 & 0.510 & 0.497 \\
\hline o,p'- DDT & Avrg EF & 0.489 & 0.531 & 0.506 \\
\hline & Sample Code & PK 333 & PK 334 & PK 335 \\
\hline & Sampling Country / Region & Malaysia & Norway & Norway \\
\hline & Landuse & secondary forest & woodland & grassland \\
\hline & Latitude & 0.120 & 68.850 & 68.850 \\
\hline & Longitude & 115.020 & 19.750 & 19.750 \\
\hline & Sample Depth (cm) & $0-5$ & $0-5$ & $0-5$ \\
\hline & SOM\% & 10.2 & 86.6 & 10.7 \\
\hline & Annual Mean Temp (C) & 27 & 1.5 & 1.5 \\
\hline TC & Avrg EF & 0.504 & 0.497 & 0.526 \\
\hline CC & Avrg EF & 0.543 & na & 0.541 \\
\hline MC5 & Avrg EF & na & 0.484 & 0.521 \\
\hline$\alpha-\mathrm{HCH}$ & Avrg EF & 0.513 & 0.550 & 0.495 \\
\hline o,p'- DDT & Avrg EF & na & 0.475 & 0.479 \\
\hline
\end{tabular}


Table S1. (continued)

\begin{tabular}{|c|c|c|c|c|}
\hline & Sample Code & PK 336 & PK 337 & PK 338 \\
\hline & Sampling Country / Region & Norway & Norway & Norway \\
\hline & Landuse & grassland & woodland & heathland \\
\hline & Latitude & 58.533 & 58.333 & 61.600 \\
\hline & Longitude & 6.417 & 8.250 & 10.167 \\
\hline & Sample Depth $(\mathrm{cm})$ & $0-5$ & $0-5$ & $0-5$ \\
\hline & SOM $\%$ & 48.7 & 95.2 & 36.4 \\
\hline & Annual Mean Temp (C) & 6.5 & 6.75 & 0.25 \\
\hline TC & Avrg EF & 0.466 & 0.406 & 0.433 \\
\hline $\mathrm{CC}$ & Avrg EF & 0.508 & 0.559 & 0.575 \\
\hline MC5 & Avrg EF & 0.436 & 0.458 & 0.440 \\
\hline$\alpha-\mathrm{HCH}$ & Avrg EF & 0.591 & 0.547 & 0.600 \\
\hline o,p'- DDT & Avrg EF & 0.493 & na & 0.557 \\
\hline & Sample Code & PK 339 & PK 340 & PK 341 \\
\hline & Sampling Country / Region & Peru & Poland & Portugal \\
\hline & Landuse & Agricultural & woodland & woodland \\
\hline & Latitude & -9.083 & 53.630 & 37.120 \\
\hline & Longitude & -77.583 & 21.480 & -8.530 \\
\hline & Sample Depth (cm) & $0-5$ & $0-5$ & $0-5$ \\
\hline & SOM \% & 3.2 & 78.1 & 15.6 \\
\hline & Annual Mean Temp (C) & 1.6 & 6.5 & 16 \\
\hline TC & Avrg EF & 0.436 & 0.392 & 0.389 \\
\hline CC & Avrg EF & 0.479 & 0.560 & 0.549 \\
\hline MC5 & Avrg EF & na & 0.431 & 0.461 \\
\hline$\alpha-\mathrm{HCH}$ & Avrg EF & 0.517 & 0.555 & 0.465 \\
\hline o,p'- DDT & Avrg EF & 0.455 & 0.486 & 0.499 \\
\hline & Sample Code & PK 342 & PK 343 & PK 344 \\
\hline & Sampling Country / Region & Scotland & S. Africa & South Africa \\
\hline & Landuse & Moorland & national park & Grassland \\
\hline & Latitude & 57.683 & -23.810 & -27.333 \\
\hline & Longitude & 5.583 & 31.580 & 32.667 \\
\hline & Sample Depth (cm) & $0-5$ & $0-5$ & $0-5$ \\
\hline & SOM\% & 6.6 & 1.3 & 2.1 \\
\hline & Annual Mean Temp (C) & 9 & 15 & 15 \\
\hline TC & Avrg EF & 0.488 & na & 0.505 \\
\hline $\mathrm{CC}$ & Avrg EF & 0.459 & 0.566 & na \\
\hline MC5 & Avrg EF & 0.763 & 0.307 & na \\
\hline$\alpha-\mathrm{HCH}$ & Avrg EF & 0.403 & na & na \\
\hline o,p'- DDT & Avrg EF & na & 0.508 & 0.537 \\
\hline
\end{tabular}


Table S1. (continued)

\begin{tabular}{|c|c|c|c|c|}
\hline & Sample Code & PK 345 & PK 346 & PK 347 \\
\hline & Sampling Country / Region & Siberia & Vietnam & Spain \\
\hline & Landuse & na & Woodland & Scrub \\
\hline & Latitude & 60.741 & 11.267 & 38.783 \\
\hline & Longitude & 89.383 & 106.033 & 2.417 \\
\hline & Sample Depth (cm) & $0-5$ & $0-5$ & $0-5$ \\
\hline & SOM \% & 3.1 & 2.2 & 4.4 \\
\hline & Annual Mean Temp (C) & -3 & 32 & 16 \\
\hline TC & Avrg EF & 0.471 & 0.506 & 0.454 \\
\hline $\mathrm{CC}$ & Avrg EF & 0.505 & 0.482 & 0.482 \\
\hline MC5 & Avrg EF & na & 0.473 & 0.452 \\
\hline$\alpha-\mathrm{HCH}$ & Avrg EF & 0.577 & 0.477 & 0.488 \\
\hline o,p'- DDT & Avrg EF & 0.481 & 0.516 & 0.568 \\
\hline & Sample Code & PK 348 & PK 349 & PK 350 \\
\hline & Sampling Country / Region & Spain & Sri Lanka & Sweden \\
\hline & Landuse & rough grasslanc & Woodland & clearing \\
\hline & Latitude & 36.850 & 8.067 & 60.500 \\
\hline & Longitude & -3.480 & 80.983 & 14.820 \\
\hline & Sample Depth (cm) & $0-5$ & $0-5$ & $0-5$ \\
\hline & SOM\% & 9.3 & 1.9 & 32.4 \\
\hline & Annual Mean Temp (C) & 16 & 30 & 3.6 \\
\hline TC & Avrg EF & 0.397 & 0.503 & 0.341 \\
\hline CC & Avrg EF & 0.562 & 0.502 & 0.455 \\
\hline MC5 & Avrg EF & 0.459 & 0.493 & 0.455 \\
\hline$\alpha-\mathrm{HCH}$ & Avrg EF & 0.500 & na & 0.655 \\
\hline o,p'- DDT & Avrg EF & 0.509 & 0.425 & na \\
\hline & Sample Code & PK 351 & PK 352 & PK 353 \\
\hline & Sampling Country / Region & Switzerland & Tenerife & Tenerife \\
\hline & Landuse & Woodland & Forest & uncultivatec \\
\hline & Latitude & 47.483 & 28.300 & 28.250 \\
\hline & Longitude & 8.433 & -16.500 & -16.800 \\
\hline & Sample Depth (cm) & $0-5$ & $0-5$ & $0-5$ \\
\hline & SOM\% & 25.6 & 12.7 & 6.7 \\
\hline & Annual Mean Temp (C) & 8.5 & 7 & 14 \\
\hline TC & Avrg EF & 0.616 & 0.479 & 0.453 \\
\hline $\mathrm{CC}$ & Avrg EF & 0.846 & 0.529 & 0.534 \\
\hline MC5 & Avrg EF & 0.460 & 0.446 & 0.481 \\
\hline$\alpha-\mathrm{HCH}$ & Avrg EF & 0.552 & 0.566 & 0.523 \\
\hline o,p'- DDT & Avrg EF & na & 0.470 & 0.463 \\
\hline
\end{tabular}


Table S1. (continued)

\begin{tabular}{|c|c|c|c|c|c|}
\hline & Sample Code & PK 354 & PK 355 & PK 356 & PK 357 \\
\hline & Sampling Country / Region & Tenerife & Thailand & Turkey & UK \\
\hline & Landuse & national park & woodland & uncultivated & grassland \\
\hline & Latitude & 28.330 & 13.400 & 36.880 & 50.780 \\
\hline & Longitude & -16.900 & 100.980 & 30.700 & -3.880 \\
\hline & Sample Depth (cm) & $0-5$ & $0-5$ & $0-5$ & $0-5$ \\
\hline & SOM\% & 1.8 & 0.6 & 6.9 & 13.5 \\
\hline & Annual Mean Temp (C) & 18 & 30 & 18.4 & 9.6 \\
\hline TC & Avrg EF & 0.487 & 0.474 & 0.361 & 0.482 \\
\hline CC & Avrg EF & 0.572 & na & 0.524 & 0.563 \\
\hline MC5 & Avrg EF & 0.489 & 0.459 & 0.483 & 0.471 \\
\hline$\alpha-\mathrm{HCH}$ & Avrg EF & na & 0.499 & 0.501 & 0.540 \\
\hline \multirow[t]{9}{*}{ o,p'- DDT } & Avrg EF & 0.540 & na & 0.513 & 0.570 \\
\hline & Sample Code & PK 358 & PK 359 & PK 360 & PK 361 \\
\hline & Sampling Country / Region & Pakistan & UK & UK & USA \\
\hline & Landuse & pasture & woodland & grassland & park \\
\hline & Latitude & 35.580 & 55.783 & 55.783 & 39.300 \\
\hline & Longitude & 72.250 & -5.533 & -5.533 & -76.600 \\
\hline & Sample Depth (cm) & $0-5$ & $0-5$ & $0-5$ & $0-5$ \\
\hline & SOM\% & 12.3 & 96.4 & 60.3 & 12 \\
\hline & Annual Mean Temp (C) & 17 & 8.8 & 13.6 & 13 \\
\hline TC & Avrg EF & 0.464 & 0.375 & 0.577 & 0.431 \\
\hline $\mathrm{CC}$ & Avrg EF & na & 0.080 & 0.312 & 0.589 \\
\hline MC5 & Avrg EF & 0.451 & 0.439 & 0.606 & 0.284 \\
\hline$\alpha-\mathrm{HCH}$ & Avrg EF & 0.512 & 0.478 & 0.890 & 0.538 \\
\hline \multirow[t]{10}{*}{$0, p^{\prime}-$ DDT } & Avrg EF & na & na & 0.456 & 0.595 \\
\hline & & & & & Form \\
\hline & Sample Code & PK 362 & PK 363 & PK 364 & PK 365 \\
\hline & Sampling Country / Region & US & USA & Vietnam & South Georgia \\
\hline & Landuse & Woodland & forest & orchard & Post industrial \\
\hline & Latitude & 42.217 & 37.200 & 10.450 & -57.283 \\
\hline & Longitude & -76.617 & -76.530 & 106.500 & -36.517 \\
\hline & Sample Depth (cm) & $0-5$ & $0-5$ & $0-5$ & $0-5$ \\
\hline & som\% & 12.2 & 5.5 & 6.5 & 41 \\
\hline & Annual Mean Temp (C) & 18 & 21 & 30 & 10 \\
\hline TC & Avrg EF & 0.482 & 0.559 & 0.489 & na \\
\hline CC & Avrg EF & 0.470 & 0.550 & na & na \\
\hline MC5 & Avrg EF & 0.391 & 0.330 & 0.336 & na \\
\hline$\alpha-\mathrm{HCH}$ & Avrg EF & 0.520 & 0.536 & 0.399 & na \\
\hline o,p'- DDT & Avrg EF & 0.540 & 0.500 & 0.523 & na \\
\hline
\end{tabular}


3 Chiral pesticides frequently undergo enantioselective degradation in soils. Prior studies to 4 characterize chiral signatures have focused on treated agricultural soils, rather than 5 background (untreated) soils, and tracking signatures in the atmosphere, for source

6 apportionment purposes. In this study, we investigated the chiral signatures in 65 background

7 soils collected from different locations across the world. The soils were taken from different 8 ecosystems (e.g., grasslands, forests) and the enantiomeric fractions (EFs) of chiral 9 chlordanes, $\alpha$-hexachlorocyclohexane $(\alpha-\mathrm{HCH})$ and o,p'-DDT were determined. Chlordanes 10 in most of the soils showed the usual pattern of enantioselective degradation seen in 11 agricultural soils, namely depletion of (+)-trans-chlordane (TC) and (-)-cis-chlordane (CC).

12 However, some samples showed opposite enantiomer degradation patterns for TC, CC and 13 chlordane compound MC5. Correlations were tested between the deviation of EFs from 14 racemic $(\mathrm{DEVrac}=$ absolute value of $0.500-\mathrm{EF})$, the percent soil organic matter $(\% \mathrm{SOM})$, 15 annual mean temperature and the ratio of TC to the more stable compound trans-nonachlor 16 (TN). Significant positive correlations were found between DEVrac and \% SOM for TC and $17 \mathrm{CC}(\mathrm{p}=0.0022$ and 0.0031$)$, but not for the other OCPs. No significant correlations were 18 found between DEVrac and annual mean temperature for any of the OCPs. DEVrac for TC 19 was negatively correlated with the TC/TN ratio, but the regression was driven by two points 20 with high ratios of TC/CC. Removing these two points resulted in a nonsignificant 21 regression. The range of $\mathrm{EFs}$ for $\mathrm{TC}, \mathrm{CC}$, and $\alpha-\mathrm{HCH}$ in soils was greater than in ambient air, 22 providing evidence of in situ degradation after atmospheric deposition in some cases. 23 Variable EFs in soil suggest that caution is needed when considering the enantiomer 24 signatures in air as a marker of volatilization of weathered soil-derived organochlorines. 


\section{Introduction}

27 Many organochlorine pesticides (OCPs) are semivolatile, hydrophobic and have long

28 environmental lifetimes in soil and water. Consequently, several OCPs have been classified as

29 persistent organic pollutants (POPs). OCPs were used heavily in the United States, Canada

30 and many other countries. Most have been banned or restricted for several years in

31 industrialized countries and are now being eliminated under the UN-ECE (United Nations

32 Economic Commission for Europe) (1) and UNEP (United Nations Environmental Program)

33 POPs Protocols (2). Nevertheless, residues in air and soils are still detectable on regional and

34 continental scales (3-18). In order to understand current sources of OCPs and other POPs in

35 the world's atmosphere, their origins must be identified. A key question is: are OCPs

36 transported from regions where they are currently applied or are they residues from past

37 applications?

39 A well established approach to investigating this issue is using enantiomers as tracers. Several

40 OCPs are chiral and are present in the environment as a mixture of two enantiomers. These

41 enantiomers have identical physicochemical properties but often have different toxicological

42 properties and rates of metabolism (19-22). Chiral OCPs are frequently degraded

43 enantioselectively in soil by microbial activity, resulting in the accumulation of nonracemic

44 residues. When these residues volatilize, their distinctive enantiomer signatures are retained

45 and reflected in the overlying air (23). Although there have been several studies of OCP

46 enantiomers in agricultural soils $(3,4,8,24)$ and their use in monitoring soil-air exchange $(5$,

$478,25,26,27)$ there are very few measurements in background soils. This is an important gap 
48 because background soils constitute a key part of the global inventory of POPs (28). Given

49 that soil microbially-mediated processes control the enantiomer composition of chiral OCPs,

50 the range of soil types and ecosystems (e.g. forests, grasslands, deserts, etc.) and the

51 variability they may encompass needs to be addressed. Background and agricultural soil types

52 often differ in OCP residue levels, nutrients, soil organic matter (SOM), microbial

53 communities and the degree of soil mixing.

54 The aim of this study was to obtain OCP enantiomer fractions in background soils from

55 diverse geographical locations where soil type, organic matter and environmental parameters

56 differ. Enantiomers of trans- and cis-chlordane (TC, CC), chlordane MC5, $\alpha$ -

57 hexachlorocyclohexane $(\alpha-\mathrm{HCH})$ and o,p'-DDT were investigated in background soils

58 collected in 37 locations in different countries and enantiomer depletions were compared to

59 reported results from farms in the midwestern United States (4). The background soils are

60 believed to have only received POPs via atmospheric deposition, and have been described

61 previously (28). Determining the chiral composition of OCPs in these soils helps provide

62 insights to the processes affecting atmospherically deposited OCPs in non-agricultural soils

63 and their influence on atmospheric enantiomer signatures when the compounds revolatilize.

\section{Materials and Methods}

$66 \underline{\text { Materials }}$

67 Chromatographic quality solvents were EMD Omnisolv® (Gibbstown, NJ, U.S.A).

68 Aluminum oxide (alumina, $0.063-0.30 \mathrm{~mm}$ ) was active neutral (EM Science, Darmstadt,

69 Germany), baked at $400{ }^{\circ} \mathrm{C}$ overnight, cooled and deactivated with $6 \% \mathrm{w} / \mathrm{w}$ HPLC grade

70 deionized water. Granular anhydrous sodium sulfate (EM Science) was baked at $400{ }^{\circ} \mathrm{C}$ 
71 overnight. Other reagents were analytical quality. Racemic standards of pure TC, $\mathrm{CC}, \alpha-\mathrm{HCH}$

72 and o,p'-DDT, achiral trans-nonachlor (TN) and technical chlordane (containing TC, CC,

73 MC5 and other components) were obtained from the U.S. Environmental Protection Agency

74 Repository for Pesticides and Industrial Chemicals, Research Triangle Park, NC, U.S.A.

75 Enantioenriched standards of $\mathrm{TC}, \mathrm{CC}$ and $\alpha-\mathrm{HCH}$ were obtained from Ehrenstorfer

76 Laboratories, Augsburg, Germany.

$78 \quad$ Soil sampling

79 Nearly 200 surface $(0-5 \mathrm{~cm})$ soil samples were collected by hand-held corer, as described in

80 Meijer et al. (28), sub-sampled and analyzed for PCBs and HCB. Sampling locations were

81 chosen to be far from potential sources such as urban/agricultural/industrial areas to ensure

82 that they would represent background levels of compounds. The remaining samples were then

83 kept frozen at Lancaster University at $-20{ }^{\circ} \mathrm{C}$, until a sub-set of 65 samples from 32 countries

84 was selected for this study, from the locations shown in Figure 1 and described in Table S1.

85 The $\%$ SOM had been determined previously $(28,30)$.

86

$87 \quad$ Analytical methods

88 Prior to chiral analysis, samples were defrosted at room temperature and 50-100 g of soil was

89 mixed with sodium sulfate and Soxhlet extracted with dichloromethane (DCM) for $16 \mathrm{~h}$.

90 Extracts were reduced to $5 \mathrm{~mL}$ using a rotary evaporator, transferred to tubes and further

91 reduced and solvent exchanged into isooctane under a gentle stream of nitrogen to a final

92 volume of $2 \mathrm{~mL}$. An initial clean up was done by vortex mixing the extract with $2 \mathrm{~mL} 15 \%$

93 fuming sulfuric acid. This was followed by cleanup and fractionation on a column of $2 \mathrm{~g}$ 
94 neutral alumina topped with $0.5 \mathrm{~cm} \mathrm{Na} \mathrm{NO}_{4}$. The column was precleaned with $15 \mathrm{~mL}$

95 petroleum ether (PE), the sample was applied and the column was eluted with PE in two

96 fractions. The first $4 \mathrm{~mL}$ (F1) was discarded to minimize the amount of waxy residue in the

97 extract and then $16 \mathrm{~mL}(\mathrm{~F} 2)$ was collected for the pesticides. F2 was reduced to $\sim 25 \mu \mathrm{L}$

98 using isooctane as the keeper solvent. Tests $(n=3)$ with a standard mixture showed that F2

99 contained $>99 \pm 1 \%$ of the $\alpha-\mathrm{HCH}, \mathrm{TC}, \mathrm{CC}$ and TN, $90 \pm 2 \%$ of the o,p'-DDT and $60 \pm 11 \%$

100 of the p,p'-DDE. The remainder of the DDE was lost in F1.

101

102 Chiral analysis

103 Enantiomer analysis was done by capillary gas chromatography - electron capture negative 104 ion mass spectrometry (GC-ECNI-MS) on a Hewlett-Packard (HP) 5890 GC-5989B MS-

105 Engine with methane as the carrier gas at a nominal pressure of 1 Torr. Sample volumes of 2 $106 \mu \mathrm{L}$ were injected splitless and the split was opened after $1 \mathrm{~min}$. Target/qualifier ions were 107 monitored as follows: chlordanes 410/412, $\alpha-\mathrm{HCH}$ 255/257 and o,p'-DDT 246/248. Peak 108 areas were integrated manually after Gaussian smoothing using HP-Chemstation software 109 (version HP G1034C). Different chiral columns were used for enantiomer separations. TC, $110 \mathrm{CC}$ and $\alpha-\mathrm{HCH}$ were run by chromatographing the samples on a primary column, with 111 confirmation on a secondary column which had different elution characteristics. Enantiomers 112 of MC5 and o,p'-DDT could only be resolved on single columns. Details are as follows:

$114 T C$ and $C C$ : Primary column BGB-172 (BGB, $15 \mathrm{~m}, 0.25 \mathrm{~mm}$ i.d., $0.25 \mu \mathrm{m}$ film thickness, 115 BGB Analytik AG, Switzerland) operating at a He carrier gas flow of $60 \mathrm{~cm} \mathrm{~s}^{-1}$. Temperature 116 program: $90{ }^{\circ} \mathrm{C}$, hold $1 \mathrm{~min}, 20{ }^{\circ} \mathrm{C} \min ^{-1}$ to $160{ }^{\circ} \mathrm{C}, 2{ }^{\circ} \mathrm{C} \min ^{-1}$ to $180{ }^{\circ} \mathrm{C}$, hold $41 \mathrm{~min}, 25{ }^{\circ} \mathrm{C}$ 
$117 \min ^{-1}$ to $225{ }^{\circ} \mathrm{C}$, hold $15 \mathrm{~min}$. Secondary column Betadex-120 (BDX, $30 \mathrm{~m}, 0.25 \mathrm{~mm}$ i.d.,

$118 \quad 0.25 \mu \mathrm{m}$ film thickness (Supelco Corporation, Bellefonte, PA, U.S.A.) operating at a He gas

119 flow of $50 \mathrm{~cm} \mathrm{~s}^{-1}$. Temperature program: $90{ }^{\circ} \mathrm{C}$, hold $1 \mathrm{~min}, 15^{\circ} \mathrm{C} \mathrm{min}^{-1}$ to $150{ }^{\circ} \mathrm{C}, 1{ }^{\circ} \mathrm{C} \mathrm{min}{ }^{-1}$

120 to $185{ }^{\circ} \mathrm{C}$, hold $25 \mathrm{~min}, 20{ }^{\circ} \mathrm{C} \min ^{-1}$ to $225^{\circ} \mathrm{C}$, hold $20 \mathrm{~min}$.

$121 \alpha-H C H$ : Primary column BGB-172, operating conditions and column details are as above.

122 Secondary column Rtx $\beta$ DEXcst (30 m, $0.25 \mathrm{~mm}$ i.d., $0.25 \mu \mathrm{m}$ film thickness, Restek

123 Corporation, Bellefonte, PA, U.S.A.) operating at a He carrier gas flow of $50 \mathrm{~cm} \mathrm{~s}^{-1}$.

124 Temperature program: $90{ }^{\circ} \mathrm{C}$, hold $1 \mathrm{~min}, 20{ }^{\circ} \mathrm{C} \mathrm{min}-1$ to $145{ }^{\circ} \mathrm{C}, 1{ }^{\circ} \mathrm{C} \mathrm{min}^{-1}$ to $170{ }^{\circ} \mathrm{C}, 20{ }^{\circ} \mathrm{C}$

$125 \min ^{-1}$ to $225{ }^{\circ} \mathrm{C}$, hold $15 \mathrm{~min}$.

126

127 MC5: Run only on the BDX column. The operating conditions and column details are as 128 above.

o, $p^{\prime}-D D T$ : Run only on the BGB column. The operating conditions and column details are as

131 above.

132

133 Results were expressed as the enantiomer fraction, EF $=$ peak areas of the $(+) /[(+)+(-)]$

134 enantiomers, for $\mathrm{TC}, \mathrm{CC}$ and $\alpha-\mathrm{HCH}$. In the case of $\mathrm{MC}$, the optical rotations are not known

135 and so the EF was calculated as the area of the first enantiomer peak divided by sum of the

136 areas of both peaks. EF is considered a superior descriptor over the enantiomer ratio (31-33).

137 A racemic $\mathrm{EF}=0.500$ whereas preferential degradation of the $(+)$ or $(-)$ enantiomer yields

138 EFs $<0.500$ and $>0.500$, respectively. 
141 Quality control issues with enantiomeric analysis are precision of the integration of the 142 enantiomer peak areas and elimination of interferences. Positive identification of enantiomer 143 elution order was made by using enantio-enriched standards for $\alpha-\mathrm{HCH}$, TC and $\mathrm{CC}$, and cod 144 liver oil for o,p'-DDT (see below). Decisions as to whether a particular soil contained 145 racemic or nonracemic residues were made by determining whether the EF for the compound 146 in question fell within or outside of the $\pm 95 \%$ C.I. for the standards. Racemic standards were 147 injected repeatedly for every five samples to determine the reproducibility in measuring EFs. 148 Average EF values of the standards were $0.498 \pm 0.004$ for TC; $0.500 \pm 0.004$ for CC; $0.493 \pm$ 1490.003 for MC5; $0.503 \pm 0.007$ for $\alpha-\mathrm{HCH}$ and $0.501 \pm 0.007$ for o,p'-DDT. The precision of 150 EF measurements for the standards, and for these OCPs in a Standard Reference Material $151(34,35)$ justifies using three decimal places in reporting. Freedom of peaks from interferences 152 was ensured by requiring that ratios of the target/qualifier ions (IRs) for each enantiomer peak 153 were within the $95 \%$ C.I. for standards for a satisfactory analysis; otherwise, the result was 154 rejected (36). Blanks were included with the soil samples, by extracting a thimble filled with 155 sodium sulfate, one for every five samples, treated in the same manner as samples. None of 156 the chiral OCPs was found in the blanks. Sample results were confirmed on a second column 157 for $\alpha-\mathrm{HCH}$, TC and CC. The average EF ratio for BGB/BDX was $0.994 \pm 0.052$ for TC $(\mathrm{n}=$ $15844)$ and $1.033 \pm 0.070$ for $\mathrm{CC}(\mathrm{n}=44)$. The average EF ratio for BGB/Rtx $\beta$ DEXcst was $1590.996 \pm 0.035$ for $\alpha-\mathrm{HCH}(\mathrm{n}=22)$. These ratios are not significantly different from 1 for TC 160 and $\alpha-\mathrm{HCH}(\mathrm{p}>0.05)$. A small, but significant $(\mathrm{p}<0.01)$, bias was shown toward higher EFs 161 of $\mathrm{CC}$ on the BGB column. Racemic standards of chiral pesticides were added to five 162 woodland and grassland soil samples before extraction. The recovered compounds had EFs 
$163 \quad$ (mean \pm s.d.): $\mathrm{TC}=0.500 \pm 0.003, \mathrm{CC}=0.501 \pm 0.005, \alpha-\mathrm{HCH}=0.502 \pm 0.003$ and o,p'-

$164 \mathrm{DDT}=0.503 \pm 0.007$. These EFs are not significantly different from racemic $(\mathrm{p}>0.05)$.

165

166 The EFs of chiral OCPs were determined in Standard Reference Material cod liver oil (SRM

167 1588) from the U.S. National Institute of Standards and Technology. The resulting EFs from

168 a single analysis were compared to published values (in parentheses, $n=5)(34): \alpha-H C H$

$1690.497(0.500 \pm 0.003)$, TC $0.545(0.532 \pm 0.001)$, CC $0.478(0.468 \pm 0.002)$, o,p'-DDT 0.620

$170(0.629 \pm 0.013)$. Note that the EF of o,p'-DDT in (34) was given incorrectly as 0.371, and a

171 correction has been published (35). Our results showed the same enantiomer depletions as

172 reported for all OCPs. Our EFs were not significantly different from published values for $\alpha$ -

$173 \mathrm{HCH}$ and o,p'-DDT $(\mathrm{p}>0.05)$ but the EFs of the chlordanes were 0.010-0.013 higher.

175 Results and Discussion

176 Global patterns of EFs

177 A wide range of EFs was found (Table 1, with details for each sample in Supplementary 178 Information Table $\mathrm{S} 1)$ with values below and above racemic $(\mathrm{EF}=0.500)$. The lowest $\mathrm{EF}$ 179 (0.080) for this study, and in the literature for soil, was for CC in a UK woodland sample (PK 180359 in Table S1). The highest EF (0.846) was also found for CC in a Switzerland woodland 181 soil (PK 351 in Table S1).

182

183 Studies on agricultural soils indicated that chiral OCP residues were usually nonracemic. The 184 general pattern in agricultural soils containing nonracemic chlordane residues was preferential 185 degradation of the $(+)$ enantiomer for $\mathrm{TC}(\mathrm{EF}<0.5)$, the $(-)$ enantiomer for $\mathrm{CC}(\mathrm{EF}>0.5)$ and 
186 the first-eluting enantiomer of MC5 on the BDX column ( $\mathrm{EF}<0.5)$, although racemic residues

187 were occasionally reported $(3,4,8,24,26,27,37,38)$. Preferential depletion of either enantiomer

188 (EF $<0.5$ or $>0.5)$ was observed for o,p'-DDT $(4,5,24,27)$. In this study, enantiomer 189 depletions of chlordanes in background soils were usually similar to agricultural soils but 190 opposite patterns (reversals) were also seen (e.g., Figure 2).

192 The resulting distribution of EFs in the background soil samples (Figure 3) showed that (+)TC 193 was preferentially depleted in $72.4 \%$ of the samples, $(-) \mathrm{TC}$ in $10.3 \%$, and racemic TC 194 occurred in $17.3 \%$. For CC, enantiomer profiles were usually reversed with depletion of 195 (-)CC (57.4\%) followed by depletion of $(+) \mathrm{CC}(27.8 \%)$ and racemic $(14.8 \%)$. The first196 eluting enantiomer of MC5 on the BDX column was depleted in $67.3 \%$ and the second197 eluting enantiomer in $25.0 \%$, while racemic MC5 was found in $7.7 \%$ of samples. In most 198 cases $\alpha-\mathrm{HCH}$ was racemic (44.6\%) or showed loss of the (-) enantiomer (37.5\%); followed 199 by the $(+)$ enantiomer (17.9\%). Residues of o,p'-DDT were divided almost equally among the 200 three EF categories, similar to what has been reported for agricultural soils $(4,5,24,27)$.

202 A previous study examined chlordane enantiomers in 1 forest, 4 grassland and 3 farm soils 203 from southern Sweden (29). Mean EFs for all soils were $0.416 \pm 0.021$ for TC and $0.541 \pm$ 2040.044 for CC. Individually, all soils but one showed preferential degradation of $(+) \mathrm{TC}$ and $205(-)$ CC, but one grassland soil showed depletion of the (-) enantiomers for both TC and CC. 206 This further indicates the nonspecific nature of the microbial degradation processes in soils. 
208 A comparison was made between grassland and woodland soils for those samples which

209 contained nonracemic residues (Figure 4). In some cases EFs differed between grassland and

210 woodland soils at a particular location (Table S1), but no significant differences ( $p>0.05)$

211 were found when comparing grassland and woodland samples in the whole sample set. Table

2122 shows the samples, taken only a few hundred meters apart, for which one or more of the

213 OCPs showed reversals in enantiomer depletions.

215 Relationship of EFs to concentrations

216 The concentrations of OCPs were very low in background soils. Quantitative determination

217 of OCPs was not done because losses occurred when sample extracts were blown down to

$218 \sim 25 \mu \mathrm{L}$, which was necessary to obtain good chromatograms in chiral analysis.

Relative concentrations of TC to the more stable TN were estimated from the "area sum of

221 TC enantiomers/area of TN" adjusted for ECNI-MS responses of the two compounds. The

222 rationale for using relative concentrations is that TC and TN differ by less than a factor of two

223 in their vapor pressures (39) and TC/TN ratios are likely to be less affected by blowdown

224 losses than absolute concentrations.

225

226 The deviation from racemic (DEVrac) of TC EFs was calculated as the absolute value of $227(0.500-\mathrm{EF})$, and this deviation is plotted vs. the TC/TN ratio in Figure 5A. The plot shows 228 that racemic TC tends to dominate in soils with high TC/TN ratios, while soils with low 229 TC/TN ratios contain both racemic and nonracemic TC. The regression $(n=58)$ has an $r^{2}=$ 2300.11 and is significant $(\mathrm{p}=0.0098)$, but is driven by a few points which have high TC/TN 
231 ratios and nearly racemic EFs. When two points with the highest TC/TN ratios are removed,

232 the regression $(n=56)$ is not significant $(\mathrm{p}=0.33)$.

234 Aigner et al. (4) present soil concentrations and enantiomer ratios (ERs) for chiral OCPs in 235 agricultural soils from the midwestern United States. A plot of DEVrac for TC (after 236 converting their ERs to EFs) vs. TC/TN (Figure 5B) $(n=24)$ has an $r^{2}=0.37$ and is significant 237 at $\mathrm{p}=0.0017(\mathrm{n}=24)$. The similarity of this plot to the global soils data in Figure 5A is 238 remarkable. Like the global soils, the regression in Figure 5B is driven by a few points with 239 high TC/TN ratios and nearly racemic EFs, and removing the two points with highest TC/TN 240 ratios results in a nonsignificant regression $(\mathrm{p}=0.11, \mathrm{n}=22)$.

242 The Aigner et al. data were further examined by plotting DEVrac vs. soil concentration for 243 TC $(n=24)$ and $o, p^{\prime}-D D T(n=14)$. The plot for TC has an $r^{2}=0.18$ and $p=0.038$. As in Figure $2445 \mathrm{~B}$ the regression for $\mathrm{TC}$ is driven by two points with high $\mathrm{TC}$ concentrations and removing 245 these two points results in a nonsignificant regression $(p=0.29)$. The o,p'-DDT plot has an $r^{2}$ $246=0.12$ and $\mathrm{p}=0.22$. A plot was also made of the Aigner et al. data for DEVrac of o,p'-DDT 247 vs. o,p'-DDT/p,p'-DDE ( $\mathrm{n}=18)$, for which $\mathrm{r}^{2}=0.23$ and $\mathrm{p}=0.043$. The significant 248 regression is driven by one point with high o,p'-DDT concentration and removing this point 249 results in a nonsignificant regression $(\mathrm{p}=0.69)$. The relationship between DEVrac for o, $\mathrm{p}^{\prime}-$ 250 DDT and the o,p'-DDT/p,p'-DDE ratio could not be determined for the global soils set 251 because $40 \%$ of p,p'-DDE was discarded within the first $4 \mathrm{~mL}$ of eluate during the alumina 252 column cleanup (see Materials and Methods section). 
254 In summary, DEVrac was not strongly related to soil concentrations (Aigner et al. data) nor to

255 labile/stable compound ratios (global soils and Aigner et al. data). This suggests that EFs are

256 not a good measure of overall degradation rates for OCPs in soil. Both enantiomers are

257 probably degraded, and nonracemic EFs result in situations where the degradation rates are

258 slightly different.

260 Relationships of EFs to \% SOM and temperature

261 Correlations were made between DEVrac, \% SOM and annual mean temperature. No 262 significant correlations between DEVrac and temperature were observed for TC, CC, MC5, $\alpha$ $263 \mathrm{HCH}$ or o,p'-DDT. The $\mathrm{p}$ values for these correlations ranged from 0.13 to 0.68 . For TC and $264 \mathrm{CC}$, significant positive correlations ( $\mathrm{p}$-values are 0.0022 and 0.0031 respectively, and $\mathrm{r}^{2}$ 265 values are 0.XX and 0.YY) were found between DEVrac and \% SOM (Figure 6A and B). No 266 significant correlation was observed between DEVrac and \% SOM for MC5, $\alpha-\mathrm{HCH}$ or o,p'267 DDT.

269 Soil microbial processes

270 The variability in EFs in global background soils raises some interesting issues concerning the 271 mechanism of enantioselective degradation in microbial communities. Differing enantiomer 272 depletions and reversals observed in closely spaced samples (e.g., Table 2) imply that 273 enantioselective degradation capabilities may develop in a localized manner in background 274 soils. The issue of scale is important, as there is limited mixing between microbial 275 communities in different locations $(40,41,42,43)$. On the basis of this information, it is 
276 hypothesized that tracking enantioselective pesticide degradation in soils may provide a useful

277 tool with which to examine the extent/scale of 'mixing' between soil microbial communities.

278 The composition and activity of soil microbial communities are influenced by many complex

279 and interacting factors - such as SOM type and burden, $\mathrm{pH}$, nutrient and redox status, the type

280 of vegetation, temperature, moisture etc. $(44,45)$. The capacity of a soil to enantioselectively

281 degrade OCPs may be influenced by the above factors. Lewis et al. (46) showed that

282 enantioselective degradation of some chiral pesticides could be reversed by manipulating

283 environmental conditions such as deforestation, warming of the soils and fertilizer addition.

284 The same authors hypothesized that the enantioselective sorption to structurally similar

285 naturally occurring chemical species in the SOM could affect the availability of enantiomers

286 for microbial transformation. These factors are likely to operate in combination as they relate

287 to microbial communities rather than individually. This is suggested by the weak or

288 nonsignificant correlations between DEVrac to temperature, \% SOM, labile/stable compound

289 ratios. Even in cases where correlations were significant, regressions accounted for only a

290 minor part of the total variance (Figures 5 and 6).

292 Implications for the fate and transport of chiral OCPs

293 This is the first large-scale study of OCP enantiomers in background soils. Results show a 294 wide range of EF values, implying a variety of degradation mechanisms and rates. Since the 295 soils were collected at locations removed from direct agrochemical applications, it is likely 296 that they acquired their burden of OCPs through atmospheric deposition. 
298 The worldwide production of chlordane was stopped in 1997, so any fresh emissions must be

299 from usage of stockpiled material. Current emissions of chlordane are thought to come from

300 two sources, nonracemic chlordanes from residues in agricultural soils and racemic

301 chlordanes from house foundation soils that were treated for termite control $(8,38)$. The latter

302 source category is reflected by racemic or nearly racemic chlordanes in the air of homes in the

303 midwestern United States (47), and in ambient air of the southern United States $(14,48$,$) . The$

304 role of background soils in the global cycling of chlordane is under investigation, but this

305 study provides some clues to sources and sinks. Chlordanes in atmospheric deposition

306 collected in southern Sweden during 1971-73 were close to racemic, whereas they are

307 nonracemic in recent times (29). Thus, over the last 30 years background soils received

308 chlordanes with EFs ranging from racemic to the nonracemic compositions.

310 The ranges of average EFs in ambient air samples collected at a large number of sites in North

311 America, Europe and the Arctic were $0.451-0.500$ for TC and $0.500-0.534$ for CC $(14,34)$,

312 with an anomolously low value for TC of 0.395 at one location (14). In North America

313 (including the Arctic), EFs of $\alpha-\mathrm{HCH}$ in ambient air range from $0.470-0.519$ (13). The fact

314 that the ranges of EFs in background soils (Table 1) are greater than those in ambient air

315 suggests that postdepositional degradation has taken place; that is, forest and grassland soils

316 are microbally processing the deposited OCPs.

317

318 Whether chlordane and other chiral OCP residues are subject to re-emission from background

319 soils is presently unknown, although emission from agricultural soils where concentrations 320 are generally much higher is well established $(5,8,23,25,27)$. If so, the enantiomer 
321 composition of global background emissions would be governed by soil concentrations and

322 diverse EF signatures (Table 1, Figure 3) resulting from different microbial degradation

323 characteristics of the soils, but at present we have insufficient soil samples to determine if

324 distinctive regional EF signatures exist.

\section{Acknowledgements}

328 Financial support to Perihan Kurt-Karakus from the Meteorological Service of Canada (MSC)

329 (Toronto, ON), Universities UK and Peel Award Committee of Lancaster University is deeply

330 acknowledged. Many thanks to Fiona Wong and Mahiba Shoeib (MSC) for sharing their

331 valuable experiences with us and for their help during analytical procedures.

332

333

334

335

336

337

338

339

340

\section{References}

(1) UNECE, Protocol on persistent organic pollutants under the 1979 convention on longrange transport air pollution. United Nations Economic Commission for Europe 1998, ECE/EB Air/60.

(2) UNEP, Preparation of an internationally legally binding instrument for implementing international action on certain persistent organic pollutants. United Nations Environment Programme 1998, UNEP/POPs/Inc. 1/6.

(3) Meijer, S.N., Halsall, C.J., Harner, T., Peters, A.J., Ockenden, W.A., Johnston, A.E. and Jones, K.C., Organochlorine pesticide residues in archived UK soil. Environ. Sci. Technol. 2001,35,1989-1995. 
(4) Aigner, E.J., Leone, A.D. and Falconer, R.L., Concentrations and enantiomeric ratios of organochlorine pesticides in soils from the U.S. Corn Belt. Environ. Sci. Technol., 1998,32,1162-1168.

(5) Bidleman, T.F., Leone, A., Soil-air exchange of organochlorine pesticides in the southern United States. Environ. Pollut. 2004,128,49-57.

(6) Offenberg, J. H., Naumova, Y. Y., Turpin, B. J., Eisenreich, S. J., Morandi, M. T., Stock , T., Colome, S. D., Winer, A. M., Spektor, D. M., Zhang, J. and Weisel, C. P., Chlordanes in the indoor and outdoor air of three U.S. cities. Environ. Sci. Technol. 2004,38,27602768 .

(7) Offenberg, J. H., Nelson, E. D., Gigliotti, C. L. and Eisenreich, S. J., Chlordanes in the Mid-Atlantic atmosphere: New Jersey 1997-1999. Environ. Sci. Technol. 2004,38,34883497.

(8) Mattina, M.I., White, J., Eitzer, B. and Lannucci-Berger, W., Cycling of weathered chlordane residues in the environment: Compositional and chiral profiles in contiguous soil, vegetation and air compartments. Environ. Tox. Chem. 2002,21,281-288.

(9) Hoh, E., Hites, R.A., Sources of toxaphene and other organochlorine pesticides in North America as determined by air measurements and potential source function contribution analysis. Environ. Sci. Technol. 2004,38,4187-4194.

(10) Van Drooge, L.B., Grimalt, J.O., Semivolatile organochlorine compounds in the free troposphere of the Northeastern Atlantic. Environ. Sci. Technol. 2002,36,1155-1161.

(11) Jaward, F.M., Farrar, N.J., Harner, T., Sweetman, A.J. and Jones, K.C., Passive air sampling of PCBs, PBDEs, and organochlorine pesticides across Europe. Environ. Sci. Technol. 2004,38,34-41. 
(12) Hung, H., Halsall, C. J., Blanchard, P., Li, H. H., Fellin, P., Stern, G. and Rosenberg B., Temporal trends of organochlorine pesticides in the Canadian Arctic atmosphere. Environ. Sci. Technol. 2002,36,5,862-868.

(13) Shen, L., Wania, F., Lei, Y. D. Teixeira, C., Muir, D. C. G. and Bidleman T. F., Hexachlorocyclohexanes in the North American atmosphere. Environ. Sci. Technol. 2004,38,965-975.

(14) Shen, L., Wania, F., Lei, Y. D. Teixeira, C., Muir, D. C. G. and Bidleman T. F., Atmospheric distribution and long-range transport behaviour of organochlorine pesticides in North America. Environ. Sci. Technol. 2005, 39, 409-420.

(15) Covaci, A., Hura, C. and Schepens, P., Selected persistent organochlorine pollutants in Romania. Sci. Total Environ. 2001,280,143-152.

(16) Garmouma, M., Poissant, L., Occurrence, temperature and seasonal trends of $\alpha$ - and $\gamma$ $\mathrm{HCH}$ in air (Quebec, Canada). Atmos. Environ. 2004,38,369-382.

(17) Harrad, M., Mao, H., Atmospheric PCBs and organochlorine pesticides in Birmingham, UK: concentrations, sources, temporal and seasonal trends. Atmos. Environ. 2004,38,1437-1445.

(18) Sofuoglu, A., Cetin, E., Bozacioglu, S.S., Sener, G.D. and Odabasi, M., Short term variation in ambient concentrations and gas/particle partitioning of organochlorine pesticides in Izmir, Turkey. Atmos. Environ. 2004,38,4483-4493.

(19) Ali, I., Gupta, V.K. and Aboul-Enein, H. Y., Chirality: A challenge for the environmental scientists. Current Sci. 2003,84,2,152-156.

(20) Kallenborn, R., Hühnerfuss, H., Chiral Environ. Pollut. 2001, First ed. 1-209, Berlin, Germany, Springer-Verlag. 
410 (21) Müller, T.A., Kohler, H.-P. E., Chirality of pollutants: effects on metabolism and fate. Appl. Microbiol. Biotechnol. 2004,64,300-316.

(22) Hegeman, W.J.M., Laane, R.W.P.M., Enantiomeric enrichment of chiral pesticides in the environment. Rev. Environ. Contam. Toxicol. 2002,173,85-116.

(23) Bidleman, T.F., Falconer, R.L., Using enantiomers to trace pesticide emission. Environ.

(24) Wiberg, K., Harner, T., Wideman, J. and Bidleman, T. F., Chiral analysis of organochlorine pesticides in Alabama soils. Chemosphere 2001,45,843-848.

(25) Eitzer, B., Ianucci-Berger, W. and Mattina, M.I., Volatilization of weathered chiral and achiral chlordane residues from soil. Environ. Sci. Technol. 2003,37,4887-4893.

(26) Meijer, S.N., Shoeib, M., Jantunen, L.M.M., Jones, K.C. and Harner, T., Air-soil exchange of organochlorine pesticides in agricultural soils:1. Field measurements using a novel in situ sampling device. Environ. Sci. Technol. 2003,37,1292-1299.

(27) Leone, A.D., Amato, S. and Falconer, R., Emission of chiral organochlorine pesticides from agricultural soils in the Cornbelt Region of the U.S. Environ. Sci. Technol.

(28) Meijer, S.N., Ockenden, W., Sweetman, A., Breivik, K., Grimalt, J. and Jones, K.C., Distribution and budget of PCBs and HCB in background surface soils, implications for sources and environmental processes. Environ. Sci. Technol. 2003,37,667-672.

(29) Bidleman, T.F., Wong, F., Backe, C., Södergren, A., Brorström-Lundén, E., Helm, P.A. and Stern, G.A., Chiral signatures of chlordanes indicate changing sources to the atmosphere the past 30 years. Atmos. Environ. 2004,38,5963-5970. 
(30) Ockenden, W., Breivik, K., Meijer, S., Steinnes, E., Sweetman, A. and Jones, K.C., The global re-cycling of persistent organic pollutants is strongly retarded by soils. Environ. Pollut. 2003,121,75-80.

(31) De Geus, J.H., Wester, P.G., De Boer J. and Brinkman, U.A., Enantiomer fractions instead of enantiomer ratios. Chemosphere 2000,41,725-727

(32) Harner, T., Wiberg, K. and Norstrom, R., Enantiomer fractions are preferred to enantiomer ratios for describing chiral signatures in environmental analysis. Environ. Sci. Technol. 2000,34,1,218-220.

(33) Ulrich, E.M., Helsel, D.R. and Foreman, W.T., Complications with using ratios for environmental data: comparing enantiomeric ratios (ERs) and enantiomer fractions (EFs). Chemosphere 2003,53,531-538.

(34) Wong, C.S., Hoekstra, P.F., Karlsson, H., Backus, S.M., Mabury, S.A. and Muir, D.C.G., Enantiomer fractions of chiral organochlorine pesticides and polychlorinated biphenyls in standard and certified reference materials. Chemosphere 2002,49,1339-1347.

(36) Bidleman, T.F., Jantunen, L.M.M., Helm, P.A., Brorström-Lundén, E. and Juntto, S., Chlordane enantiomers and temporal trends of chlordane isomers in arctic air. Environ. Sci. Technol. 2002,36,539-544.

(37) Falconer, R.L., Bidleman, T.F. and Szeto, S.Y., Chiral pesticides on soils of the Fraser 469 Valley, British Columbia. J. Agric. Food. Chem. 1997,45,1946-1951. 
(38) Eitzer, B. D., Mattina, M. I. and Iannucci-Berger ,W., Compositional and chiral profiles of weathered chlordane residues in soil. Environ. Toxic. Chem. 2001,20,2198-2204.

(39) Hinckley, D.A., Bidleman, T.F., Foreman, W.T., Tuschall, J.R.. Determination of vapor pressures for nonpolar and semipolar organic compounds from gas chromatographic retention data. J. Chem. Eng. Data, 1990, 35, 232-237

(40) Morris, S.J. Spatial distribution of fungal and bacterial biomass in southern Ohio hardwood forest soils: fine scale variability and microscale patterns. Soil Biol. Biochem. 1999,31,1375-1386.

(41) Smalla, K., Sobecky, P.A., The prevelance and diversity of mobile genetic elements in bacterial communities of different environmental habitats: insights gained from different methodological approaches. FEMS Microbiol. Ecol. 2002,42,165-175.

(42) Franklin, R,B., Mills, A.L., Multi-scale variation in spatial heterogeneity for microbial community structure in an eastern Virginia agricultural field. FEMS Microbiol. Ecol. 2003,44,335-346.

(43) Nunan, N., Wu, K., Young, I.M., Crawford, J. W. and Ritz, K., Spatial distribution of bacterial communities and their relationships with the micro-architecture of soil. FEMS Microbiol. Ecol. 2003,44,203-215.

(44) Andersson, S., Nilsson, S.I., Influence of $\mathrm{pH}$ and temperature on microbial activity, substrate availability of soil-solution bacteria and leaching of dissolved organic carbon in a mor humus. Soil Biol. Biochem. 2001,33,1181-1191.

(45) Grayston, S. J., Griffith, G.S., Mawdsley, J.L., Campbell, C.D. and Bardgett, R.D., Accounting for variability in soil microbial communities of temperate upland grassland ecosystems. Soil Biol. Biochem. 2001,33,533-551. 
505

506
(46) Lewis, D.L., Garrison, A.W., Wommack, K.E., Whittemore, A., Steudler, P. and Melillo, J., Influence of environmental changes on degradation of chiral pollutants in soils. Nature 1999,401,898-901.

(47) Leone, A.D., Ulrich, E.M., Bodnar, C.E., Falconer, R.L. and Hites, R.A., Organochlorine pesticide concentrations and enantiomer fractions for chlordane in indoor air from the US cornbelt. Atmos. Environ. 2000,34,4131-4138.

(48) Jantunen, L.M.M., Bidleman, T.F., Harner, T. and Parkhurst, W.J., Toxaphene, chlordane, and other organochlorine pesticides in Alabama air. Environ. Sci. Technol. 2000,34,5097-5105. 
534 Figure 1: Locations of the samples. Sample details (see Table S1; x1, x2 etc. indicate the 535 number of samples in each locality): Antarctica x1, Australia x3, Bolivia x2, Brazil x4, 536 Canada x8, Chile x1, Cyprus x1, Ethiopia x1, France x1, Georgia x1, Germany x2, Ghana x2, 537 Greenland x1, Iceland x1, Japan x2, Malaysia x1, Norway x5, Pakistan x1, Peru x1, Poland 538 x1, Portugal x1, Siberia x1, South Africa x2, Spain x5 (including Tenerife), Sri Lanka x1, 539 Sweden x1, Switzerland x1, Thailand x1, Turkey x1, United Kingdom (including England, 540 Ireland, Scotland) x4, USA (including Alaska and Hawaii) x5, Vietnam x2

543 Figure 2: Chromatograms of chlordane enantiomers on a BDX column A: Sample showing 544 "normal or most common" degradation profile (woodland soil from Poland), B: Sample 545 showing reversed degradation preference for TC and CC enantiomers (grassland soil from the 546 U.K.), C: Sample showing a reversed degradation preference for TC and extensive 547 degradation of both CC enantiomers (forest soil from Australia), D: technical chlordane.

549 Figure 3: Distribution of OCP EFs in background soils, \% of total samples.

551 Figure 4: Comparison of EFs in all grassland and woodland soils for samples containing 552 nonracemic residues, separated according to EFs $<0.5$ or $<0.5$. The number of samples is 553 shown above the bars and vertical lines indicate \pm one standard deviation. 
555 Figure 5: Correlation between the deviation of TC EFs from racemic and the TC/TN ratio,

556 (A) global background soil data $\left(\mathrm{r}^{2}=0.11, \mathrm{p}=0.0098\right)$ (B) midwest U.S.A. agricultural soils

557 (4) $\left(\mathrm{r}^{2}=0.37, \mathrm{p}=0.0017\right)$.

558

559 Figure 6: Correlation between the deviation of EFs from racemic vs \% SOM (A) for TC

$560\left(\mathrm{r}^{2}=0.16, \mathrm{p}=0.0022\right)$ and $(\mathrm{B})$ for $\mathrm{CC}\left(\mathrm{r}^{2}=0.16, \mathrm{p}=0.0031\right)$.

561

562

563

564

565

Figure 1

566

567

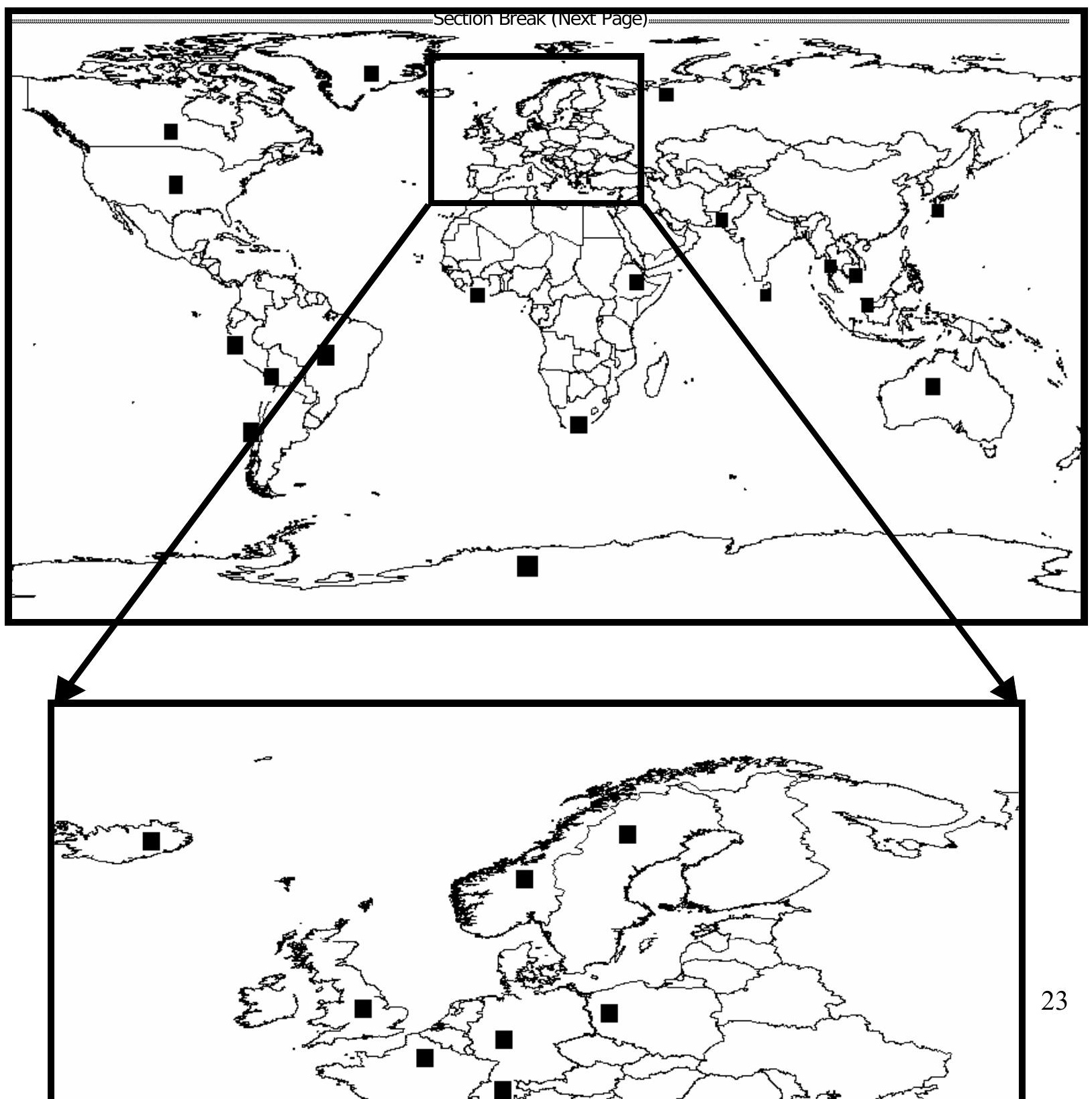


Figure 2

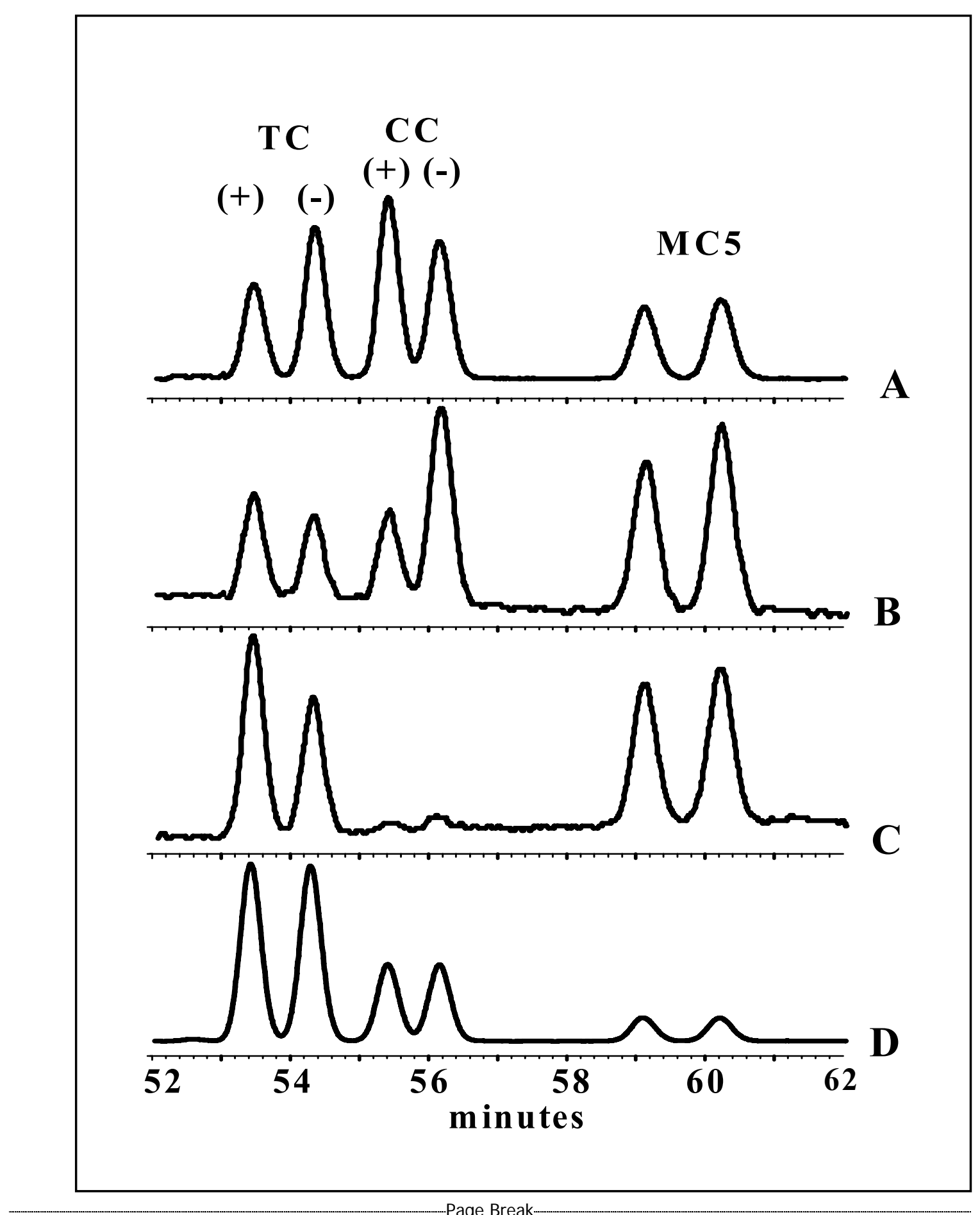

Figure 3 


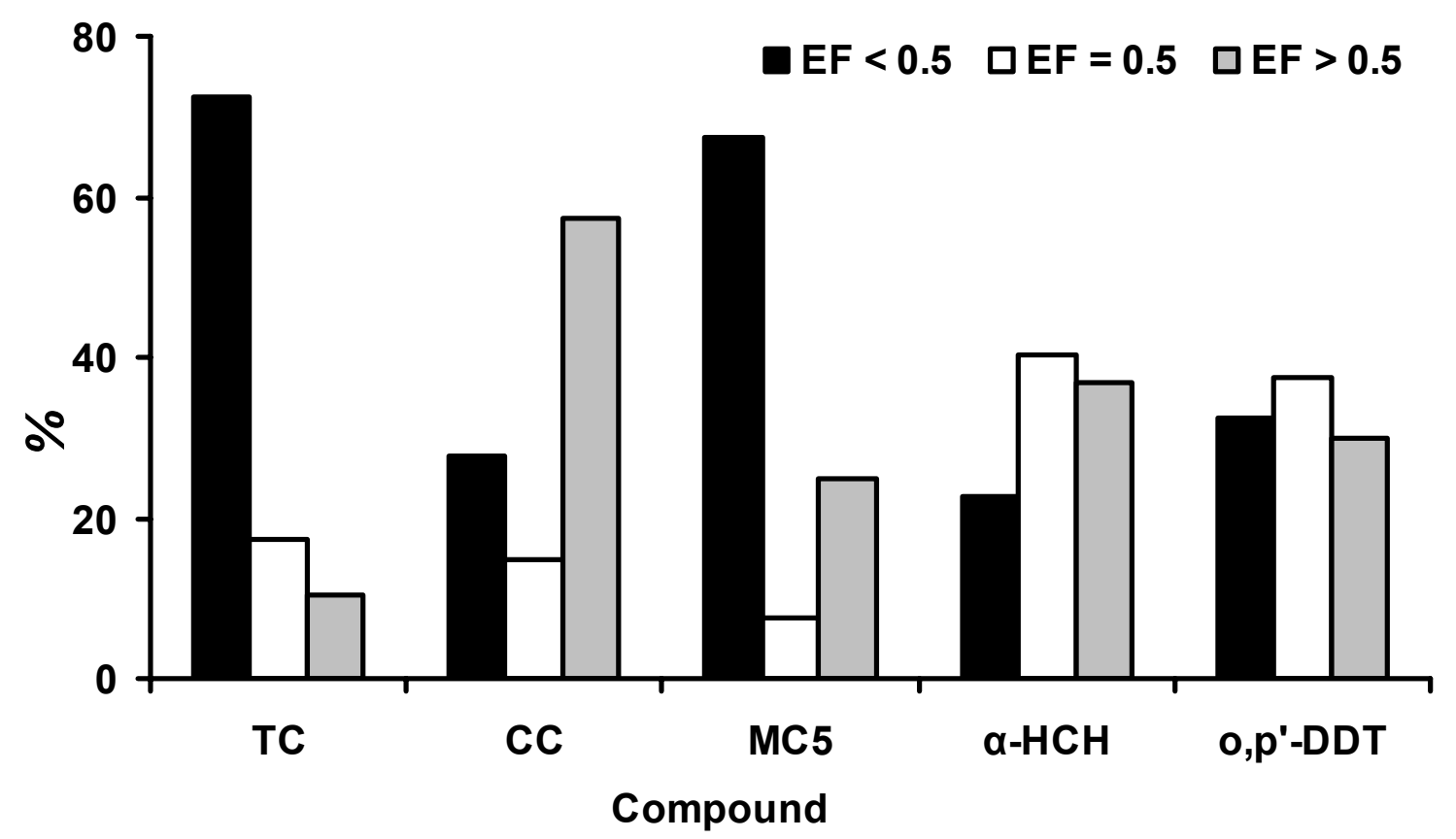

Page Break

Figure 4

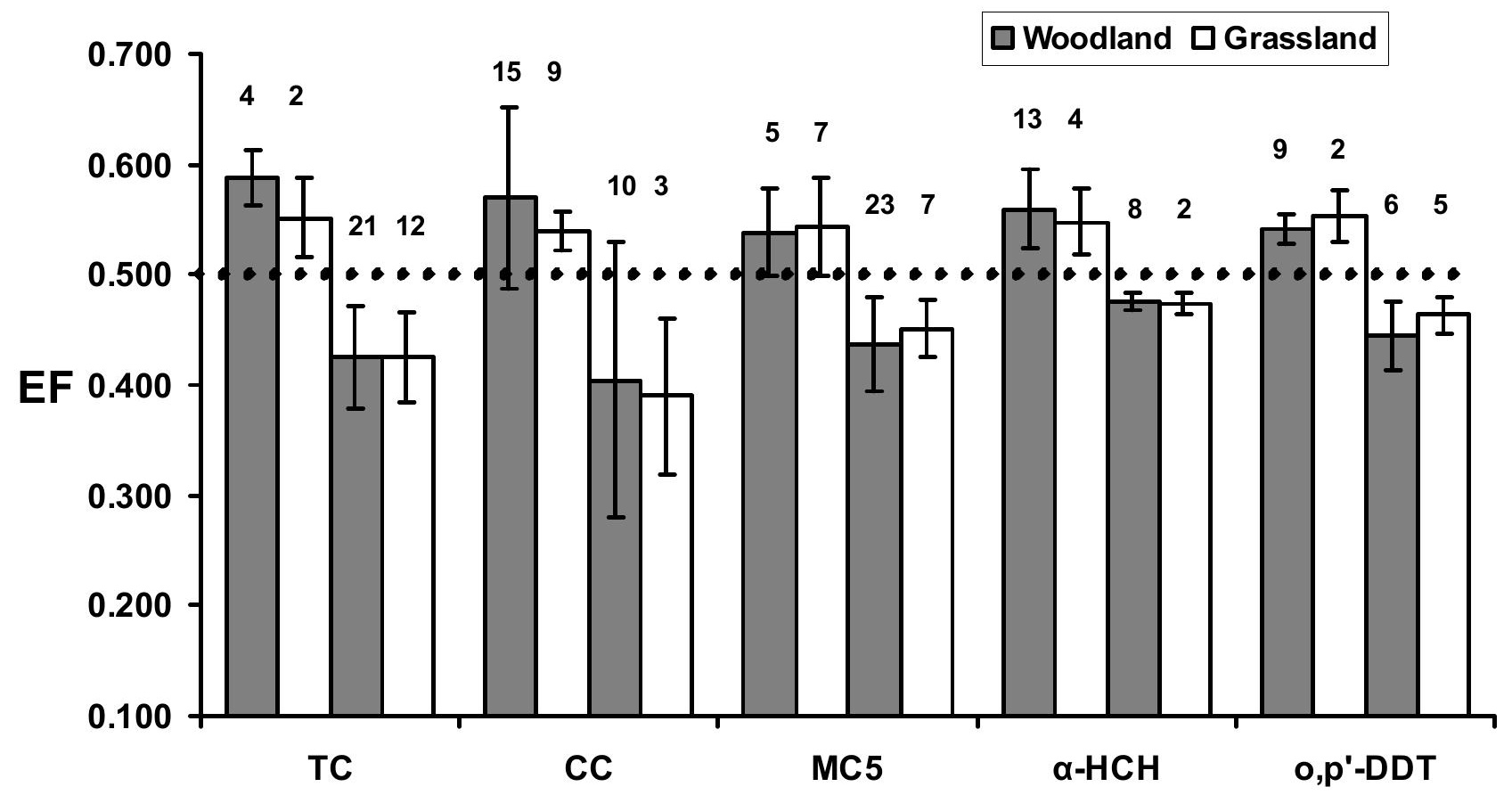



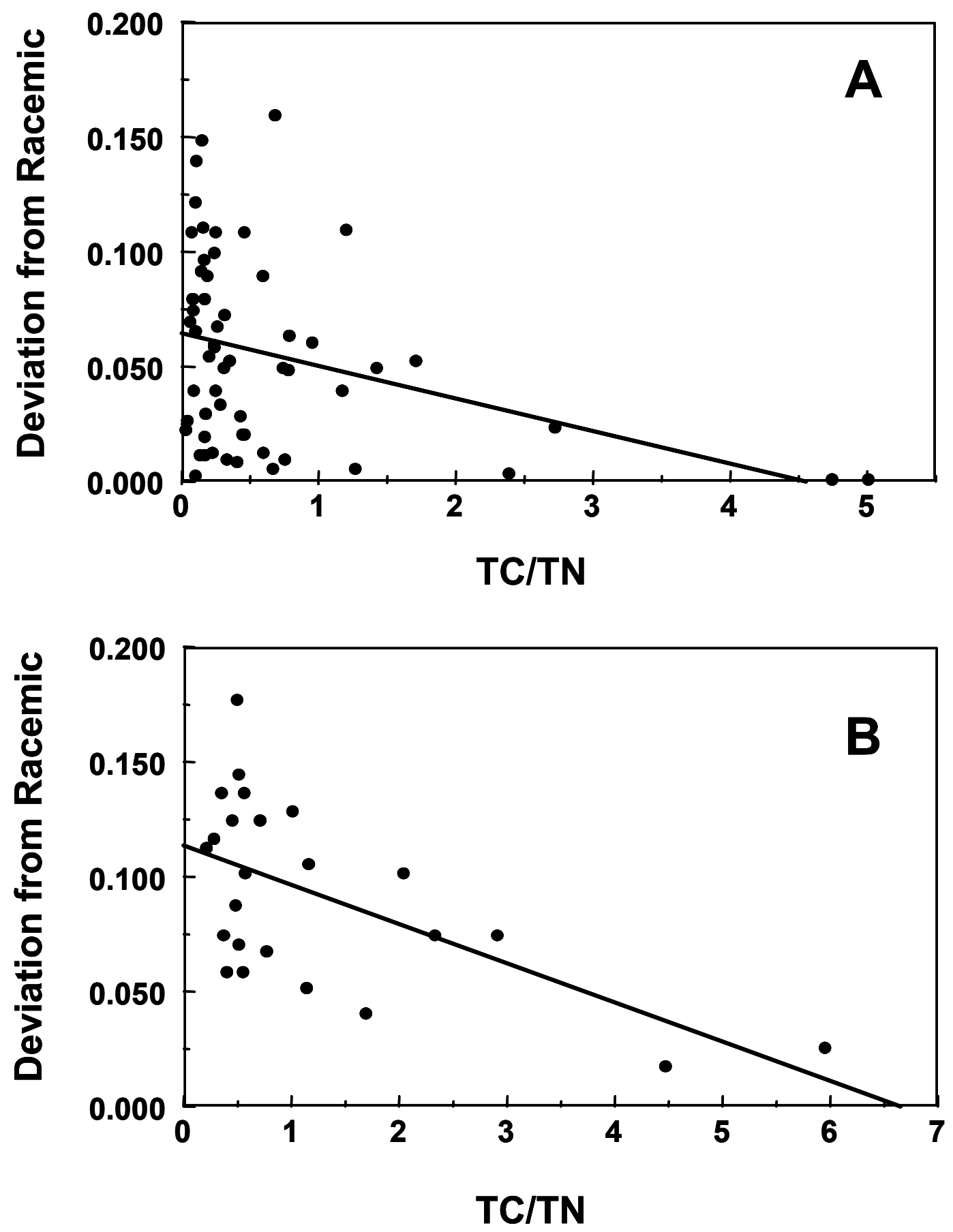

Figure 6 

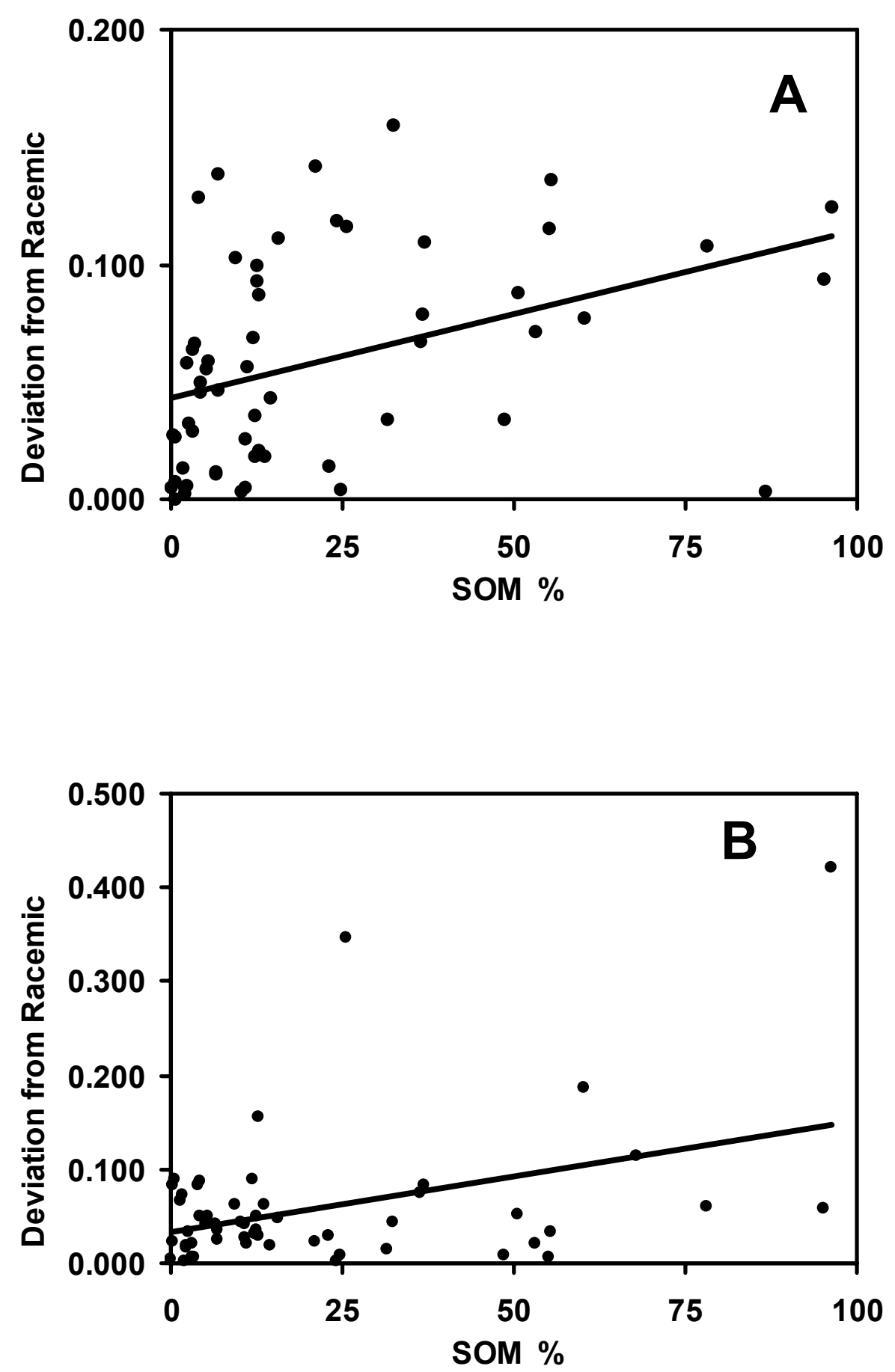

Table 1: Summary statistics for EFs of OCPs in the global background soil samples 


\begin{tabular}{|l|c|c|c|c|c|}
\hline & \multicolumn{5}{|c|}{ Compounds } \\
\hline Samples & TC & CC & MC5 & $\boldsymbol{\alpha}$-HCH & o,p'-DDT \\
\hline EF Range & $0.391-0.616$ & $0.08-0.846$ & $0.284-0.763$ & $0.403-0.890$ & $0.393-0.595$ \\
\hline Mean & 0.457 & 0.509 & 0.469 & 0.514 & 0.501 \\
\hline Std Dev. & 0.062 & 0.094 & 0.077 & 0.041 & 0.041 \\
\hline N & 58 & 54 & 52 & 56 & 40 \\
\hline
\end{tabular}

Page Break

Table 2. Sample pairs for which one or more of the OCPs showed reversals in enantioselective degradation

\begin{tabular}{|c|c|c|c|c|c|c|c|}
\hline \multirow{2}{*}{$\begin{array}{c}\text { Sample } \\
\text { Code }\end{array}$} & \multirow[t]{2}{*}{ Country } & \multirow[t]{2}{*}{ Land Use } & \multicolumn{5}{|c|}{ Avrg. EF } \\
\hline & & & TC & $\mathrm{CC}$ & MC5 & $\alpha-\mathrm{HCH}$ & o,p'-DDT \\
\hline PK311 & Canada & Woodland & 0.358 & 0.523 & 0.510 & 0.475 & 0.547 \\
\hline PK317 & Canada & Grassland & 0.382 & 0.498 & 0.532 & 0.496 & 0.465 \\
\hline PK314 & Canada & Grassland & 0.407 & 0.550 & 0.441 & 0.467 & 0.507 \\
\hline PK318 & Canada & Pasture & 0.442 & 0.517 & 0.524 & 0.524 & na \\
\hline PK334 & Norway & Woodland & 0.497 & na & 0.484 & 0.550 & 0.475 \\
\hline PK335 & Norway & Grassland & 0.526 & 0.541 & 0.521 & 0.495 & 0.479 \\
\hline PK359 & UK & Woodland & 0.375 & 0.080 & 0.439 & 0.478 & na \\
\hline PK360 & UK & Grassland & 0.577 & 0.312 & 0.606 & 0.890 & 0.456 \\
\hline
\end{tabular}

na: not available 